\title{
The origin of embryonic and fetal myoblasts: a role of Pax3 and Pax7
}

\author{
Graziella Messina and Giulio Cossu ${ }^{1}$ \\ Division of Regenerative Medicine, San Raffaele Scientific Institute, Milan 20132, Italy; Department of Biology, University of \\ Milan, Milan 20122, Italy
}

\begin{abstract}
Skeletal muscle is a heterogeneous tissue composed of individual muscle fibers, diversified in size, shape, and contractile protein content, to fulfill the different functional needs of the vertebrate body. This heterogeneity derives from and depends at least in part on distinct classes of myogenic progenitors; i.e., embryonic and fetal myoblasts and satellite cells whose origin and lineage relationship have been elusive so far. In this issue of Genes \& Development, Hutcheson and colleagues (pp. 997-1013) provide a first answer to this question.
\end{abstract}

Skeletal muscle fibers are formed throughout the vertebrate life span, during either development or regeneration; however, morphogenesis occurs during prenatal development in successive, distinct though overlapping steps involving different types of myoblasts: embryonic myoblasts, fetal myoblasts, and satellite cells.

While the primary myotome-composed of differentiated, mononucleated myocytes-forms in a Pax3/7independent way (Gros et al. 2005; Relaix et al. 2005), fusion into multinucleate muscle fibers begins at around embryonic day 11 (E11) in the mouse and characterizes "embryonic" or primary myogenesis necessary to establish the basic muscle pattern. It is sill unknown whether myotomal cells are later incorporated into primary fibers. Fetal myogenesis is characterized by growth and maturation of each muscle anlagen and by the onset of innervation. This second wave of myogenesis (also called secondary myogenesis) takes place between E14.5 and E17.5 (in the mouse) and involves the fusion of fetal myoblasts either with each other to form secondary fibers (initially smaller and surrounding primary fibers) or with primary fibers. At the end of this phase, newly formed basal lamina surrounds each individual fiber, and now satellite cells can be morphologically identified as mononucleated cells lying between the basal lamina and the myofiber plasma membrane. These adult myoblasts are responsible for postnatal growth and regeneration of the muscle fiber. Previous work from different laboratories

[Keywords: Pax3; Pax7; $\beta$-catenin; limb; myogenesis]

Corresponding author.

E-MAIL cossu.giulio@hsr.it; FAX 390226434621.

Article is online at http://www.genesdev.org/cgi/doi/10.1101/gad.1797009. identified specific features of embryonic myoblasts, fetal myoblasts, and satellite cells that characterize them as distinct classes of myogenic cells (for review, see Cossu and Molinaro 1987; Stockdale 1992; Miller et al. 1999; Cossu and Biressi 2005). Myoblasts were initially identified and classified based on their morphology, response to extrinsic signaling molecules, and drug sensitivity, and the expression of different isoforms of myosin heavy chains (MyHC) and muscle enzymes. More recently, a genome-wide expression analysis carried out on purified embryonic and fetal myoblasts (Biressi et al. 2007) identified many differentially expressed genes, clearly revealing that embryonic and fetal myoblasts are intrinsically different populations of myoblasts with distinct genetic programs. This observation raised the possibility that embryonic and fetal (as well as adult) myoblasts may derive from different, though possibly related, progenitor populations.

\section{The role of Pax3 and Pax7 in myogenesis}

In the last 10 years, research on muscle progenitors has focused on the two closely related paired domain homeobox transcription factors: Pax3 and Pax7. Their role in different aspects of myogenesis has been widely studied: Pax3 is required for myogenic specification upstream of $M y o D$ (Tajbakhsh et al. 1997), somite segmentation, dermomyotome formation (Tajbakhsh and Buckingham 2000; Schubert et al. 2001; Relaix et al. 2004), limb musculature development (Franz 1993; Bober et al. 1994; Goulding et al. 1994; Relaix et al. 2004), and $M y o D$ and Myf5 expression (Maroto et al. 1997; Bajard et al. 2006), whereas $\operatorname{Pax} 7$ is necessary for the maintenance of adult satellite cells (Seale et al. 2000; Oustanina et al. 2004; Relaix et al. 2006). Moreover, the continued growth of muscles that occurs during prenatal and postnatal life has been attributed recently to a population of muscle progenitors already present at the embryonic stage (Gros et al. 2005; Kassar-Duchossoy et al. 2005; Relaix et al. 2005; Schienda et al. 2006). These skeletal muscle progenitor cells arise in the central part of the dermomyotome, coexpress Pax3 and Pax7, can differentiate into skeletal muscle fibers during embryogenesis, and are present as a reserve cell population within the growing muscle mass during prenatal and postnatal life. In the 
Pax3/Pax 7 double knockout mice, only the primary myotome forms, while all the subsequent phases of myogenesis are compromised; it has therefore been proposed that all the cells of the myogenic lineage may derive from this Pax3/Pax7-positive population of myogenic progenitors. The fate of the $\mathrm{Pax} 3^{+}$cells was followed by using Pax $3{ }^{\mathrm{GFP}}$ mice in which the GFP is initially expressed in Pax3-expressing cells; however, because of its stability, GFP expression continues beyond the transient expression of the Pax3 gene product (Relaix et al. 2005). In conclusion, it appears that Pax 3 and Pax7 have partially overlapping and partially unique functions in myogenic progenitors; they are both down-regulated during myogenic differentiation, following myogenic regulatory factor (MRF) expression. Despite this abundant information, the specific role that Pax3 and Pax7 play in the specification of embryonic, fetal, and adult myoblasts remained to be investigated. In this issue of Genes \& Develpment, Hutcheson et al. (2009) provide a first answer to this question and, based on previous observations (Kardon et al. 2002), also investigate whether Pax3 and Pax7 progenitors also give rise to other cell types.

\section{Genetic labeling and ablation of myogenic progenitors}

Hutcheson et al. (2009) used genetic lineage tracing and ablation in mice to highlight the developmental origin of embryonic and fetal myoblasts in the limb. By using $\mathrm{Pax} 3^{\mathrm{Cre}}$ and the Pax $7^{\mathrm{iCre}}$ mice crossed with the R26R ${ }^{\mathrm{Lacz}}$ reporter mice, they confirm a temporal difference in Pax3 and Pax7 expression in line with the idea that $\mathrm{Pax}^{+}$and $\mathrm{Pax}^{+}$cells could differentially contribute to myogenic lineages. Indeed, several investigators had shown that cells in the epaxial and hypaxial edges of the dermomyotome, and also cells migrating to the limb, express Pax3 but not Pax7 (for review, see Buckingham and Relaix 2007). However, lineage ablation analysis (using the $\mathrm{R} 26 \mathrm{R}^{\mathrm{DTA} /+}$ mice) demonstrates the existence of $\mathrm{Pax}^{+} \mathrm{Pax}^{-}$somitic cells required for embryonic myogenesis and of $\mathrm{Pax} 3^{+} \mathrm{Pax} 7^{+}$ cells required for fetal and subsequently adult myogenesis. These $\mathrm{Pax} 7^{+}$cells derive from $\mathrm{Pax} 3^{+}$cells but no longer express Pax3, as Pax3 is down-regulated after E13.5. Thus, in the limb, embryonic and fetal myoblasts arise from developmentally distinct, although related, progenitors (Fig. 1). Moreover, the lineage analysis revealed that the $\mathrm{Pax}^{+}$, but not the Pax $7^{+}$, cells in the limb are bipotential, contributing to both muscle and endothelial cell lineage, suggesting that these $\mathrm{Pax}^{+}$cells in the limb retain the properties of their sisters in the hypaxial dermomyotome initially (Kardon et al. 2002). This important result leads to a crucial and yet unanswered question: Although Pax3 is a key regulator of skeletal muscle development (Maroto et al. 1997; Tajbakhsh et al. 1997; Bajard et al. 2006; Buchberger et al. 2007), in vivo expression of this gene in somitic cells is not, per se, sufficient to commit these cells toward a myogenic fate (since also endothelial cells are generated), strongly suggesting that additional extrinsic cues are needed to dictate the choice between myogenic and endothelial differentiation. The role of $\mathrm{Pax} 7$ in fetal myogenesis is consistent with previous expression data (Horst et al. 2006; Biressi et al. 2007). Nevertheless, in the Pax7-null mouse, in which adult myogenesis and regeneration are seriously compromised, fetal myogenesis is not (Seale et al. 2000; Oustanina et al. 2004; Relaix et al. 2006). Hutcheson et al. (2009) suggest that during fetal myogenesis, Pax $7^{+\prime}$ s function either is not essential or is compensated

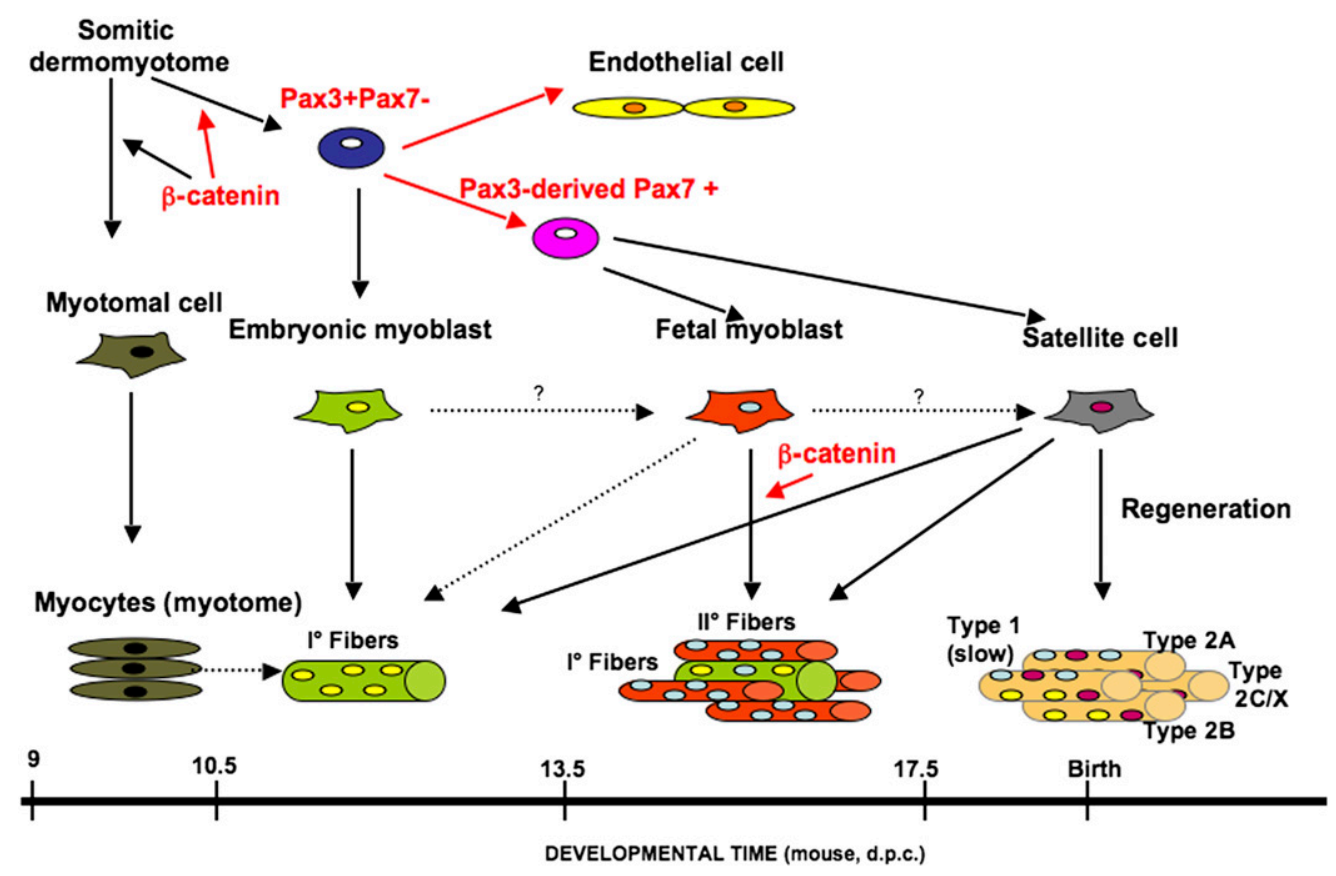

Figure 1. A scheme of the possible lineage relationships of skeletal myoblasts (and the role of $\beta$-catenin). The steps identified by the present study are shown in red. 
by other proteins, the most likely candidate being Pax3. In other words, Pax3 would be essential for embryonic myogenesis and Pax7 for adult myogenesis, whereas during the fetal period the two genes would share redundant functions.

\section{$\beta$-Catenin is required for embryonic but not fetal myogenesis}

The study by Hutcheson et al. (2009) goes on to show a $\beta$-catenin requirement for determination, migration, and proliferation of the Pax3/Pax7-expressing cells. Different studies have demonstrated the importance of Wnt/ $\beta$-catenin signaling for muscle determination (Maroto et al. 1997; Tajbakhsh et al. 1997; Borello et al. 1999, 2006; Chen et al. 2005; Brunelli et al. 2007), and for dermomyotome and myotome formation (Ikeya and Takada 1998; Linker et al. 2003; Schmidt et al. 2004; Otto et al. 2006). Here, Hutcheson et al. (2009) compare the effects of $\beta$-catenin deletion or activation driven by either $\mathrm{Pax} 3^{\mathrm{Cre}}$ or $\mathrm{Pax} 7^{\mathrm{iCre}}$ to test the role of $\mathrm{Wnt} /$ $\beta$-catenin signaling in embryonic and fetal myoblast differentiation. Results show that $\beta$-catenin is necessary for dermomyotome development, as predictable from previous work; once in the limb, however, $\beta$-catenin is no longer required for embryonic myoblasts, while $\mathrm{Pax} 7^{+}$ fetal myoblasts (and the fibers they form) are reduced in number in the absence of $\beta$-catenin signaling, suggesting a role in mediating proliferation signals. It should be noted that the work has been carried out on limb myoblasts: Although a similar scenario may exist of myoblasts in the trunk, this remains to be demonstrated.

\section{Questions for the future}

The study by Hutcheson et al. (2009) adds an important piece to the complex and still confusing puzzle of muscle development by defining the role of $\mathrm{Pax} 3 / 7$ genes and $\beta$-catenin in embryonic and fetal myoblasts (Fig. 1). Several open questions remain: What is the fate of the $\mathrm{Pax}^{+}{ }^{+} \mathrm{Pax} 7^{-}$-derived, Myf5 ${ }^{+}$embryonic myoblasts? Do they all differentiate, or rather contribute to later (fetal and adult) myogenic cells? Do all satellite cells derive from Pax3/7 embryonic/fetal myoblasts? Could other cell types feed into this compartment and be recognized as part of the myoblast population simply because they activate Pax3 and/or Pax7? Clearly, more markers and more lineage tracing experiments are needed to answer these questions. Equally important will be the identification of new molecules or molecular pathways downstream from Pax3 and/or Pax7 and responsible for myoblast diversification. In this perspective, it would be important to understand whether Pax3 alone is sufficient to rescue fetal myogenesis in Pax7-null mice or whether yet-to-be-identified additional molecules may cooperate with it in this role. New data will answer these questions in a hopefully near future.

\section{Acknowledgments}

We acknowledge Margaret Buckingham for the critical reading of the manuscript.

\section{References}

Bajard, L., Relaix, F., Lagha, M., Rocancourt, D., Daubas, P., and Buckingham, M.E. 2006. A novel genetic hierarchy functions during hypaxial myogenesis: Pax3 directly activates Myf5 in muscle progenitor cells in the limb. Genes \& Dev. 20: 24502464.

Biressi, S., Tagliafico, E., Lamorte, G., Monteverde, S., Tenedini, E., Roncaglia, E., S. Ferrari, Cusella-De Angelis, M.G., Tajbakhsh, S., and Cossu, G. et al. 2007. Intrinsic phenotypic diversity of embryonic and fetal myoblasts is revealed by genome-wide gene expression analysis on purified cells. Dev. Biol. 304: 633651.

Bober, E., Franz, T., Arnold, H.H., Gruss, P., and Tremblay, P. 1994. Pax-3 is required for the development of limb muscles: A possible role for the migration of dermamyotomal muscle progenitor cells. Development 120: 603-612.

Borello, U., Coletta, M., Tajbakhsh, S., Leyns, L., De Robertis, E.M., Buckingham, M., and Cossu, G. 1999. Transplacental delivery of the Wnt antagonist Frzb1 inhibits development of caudal paraxial mesoderm and skeletal myogenesis in mouse embryos. Development 126: 4247-4255.

Borello, U., Berarducci, B., Murphy, P., Bajard, L., Buffa, V., Piccolo, S., Buckingham, M., and Cossu, G. 2006. The Wnt/ $\beta$-catenin pathway regulates Gli-mediated Myf5 expression during somitogenesis. Development 133: 3723-3732.

Brunelli, S., Relaix, F., Baesso, S., Buckingham, M., and Cossu, G. 2007. $\beta$ Catenin independent activation of MyoD in presomitic mesoderm requires PKC and depends on Pax3 transcriptional activity. Dev. Biol. 304: 604-614.

Buchberger, A., Freitag, D., and Arnold, H.H. 2007. A homeopaired domain-binding motif directs Myf5 expression in progenitor cells of limb muscle. Development 134: 11711180.

Buckingham, M. and Relaix, F. 2007. The role of Pax genes in the development of tissues and organs: Pax 3 and Pax7 regulate muscle progenitor cell functions. Annu. Rev. Cell Dev. Biol. 23: 645-673.

Chen, A.E., Ginty, D.D., and Fan, C.M. 2005. Protein kinase A signalling via CREB controls myogenesis induced by Wnt proteins. Nature 433: 317-322.

Cossu, G. and Biressi, S. 2005. Satellite cells, myoblasts and other occasional myogenic progenitors: Possible origin, phenotypic features and role in muscle regeneration. Semin. Cell Dev. Biol. 16: 623-631.

Cossu, G. and Molinaro, M. 1987. Cell heterogeneity in the myogenic lineage. Curr. Top. Dev. Biol. 23: 185-208.

Franz, T. 1993. The Splotch (Sp1H) and Splotch-delayed (Spd) alleles: Differential phenotypic effects on neural crest and limb musculature. Anat. Embryol. (Berl.) 187: 371-377.

Goulding, M., Lumsden, A., and Paquette, A.J. 1994. Regulation of Pax-3 expression in the dermomyotome and its role in muscle development. Development 124: 2387-2395.

Gros, J., Manceau, M., Thome, V., and Marcelle, C. 2005. A common somitic origin for embryonic muscle progenitors and satellite cells. Nature 435: 954-958.

Hutcheson, D.A., Zhao, J., Merrell, A., Haldar, M., and Kardon, G. 2009. Embryonic and fetal limb myogenic cells are derived from developmentally distinct progenitors and have different requirements for $\beta$-catenin. Genes \& Dev. (this issue). doi: $10.1101 / \mathrm{gad} .1769009$.

Horst, D., Ustanina, S., Sergi, C., Mikuz, G., Juergens, H., Braun, T., and Vorobyov, E. 2006. Comparative expression analysis of Pax3 and Pax7 during mouse myogenesis. Int. J. Dev. Biol. 50: $47-54$. 
Ikeya, M. and Takada, S. 1998. Wnt signaling from the dorsal neural tube is required for the formation of the medial dermomyotome. Development 125: 4969-4976.

Kardon, G., Campbell, J.K., and Tabin, C.J. 2002. Local extrinsic signals determine muscle and endothelial cell fate and patterning in the vertebrate limb. Dev. Cell 3: 533-545.

Kassar-Duchossoy, L., Giacone, E., Gayraud-Morel, B., Jory, A., Gomes, D., and Tajbakhsh, S. 2005. Pax3/Pax7 mark a novel population of primitive myogenic cells during development. Genes \& Dev. 19: 1426-1431.

Linker, C., Lesbros, C., Stark, M.R., and Marcelle, C. 2003. Intrinsic signals regulate the initial steps of myogenesis in vertebrates. Development 130: 4797-4807.

Maroto, M., Reshef, R., Munsterberg, A.E., Koester, S., Goulding, M., and Lassar, A.B. 1997. Ectopic Pax-3 activates MyoD and Myf-5 expression in embryonic mesoderm and neural tissue. Cell 89: 139-148.

Miller, J., Schaefer, L., and Dominov, J. 1999. Seeking muscle stem cells. Curr. Top. Dev. Biol. 43: 191-219.

Oustanina, S., Hause, G., and Braun, T. 2004. Pax7 directs postnatal renewal and propagation of myogenic satellite cells but not their specification. EMBO J. 23: 3430-3439.

Otto, A., Schmidt, C., and Patel, K. 2006. Pax3 and Pax7 expression and regulation in the avian embryo. Anat. Embryol. (Berl.) 211: 293-310.

Relaix, F., Rocancourt, D., Mansouri, A., and Buckingham, M. 2004. Divergent functions of murine Pax3 and Pax7 in limb muscle development. Genes \& Dev. 18: 1088-1105.

Relaix, F., Rocancourt, D., Mansouri, A., and Buckingham, M. 2005. A Pax3/Pax7-dependent population of skeletal muscle progenitor cells. Nature 435: 948-953.

Relaix, F., Montarras, D., Zaffran, S., Gayraud-Morel, B., Rocancourt, D., Tajbakhsh, S., Mansouri, A., Cumano, A., and Buckingham, M. 2006. Pax3 and Pax7 have distinct and overlapping functions in adult muscle progenitor cells. $J$. Cell Biol. 172: 91-102.

Schienda, J., Engleka, K.A., Jun, S., Hansen, M.S., Epstein, J.A., Tabin, C.J., Kunkel, L.M., and Kardon, G. 2006. Somitic origin of limb muscle satellite and side population cells. Proc. Natl. Acad. Sci. 103: 945-950.

Schmidt, C., Stoeckelhuber, M., McKinnell, I., Putz, R., Christ, B., and Patel, K. 2004. Wnt 6 regulates the epithelialisation process of the segmental plate mesoderm leading to somite formation. Dev. Biol. 271: 198-209.

Schubert, F.R., Tremblay, P., Mansouri, A., Faisst, A.M., Kammandel, B., Lumsden, A., Gruss, P., and Dietrich, S. 2001. Early mesodermal phenotypes in splotch suggest a role for Pax3 in the formation of epithelial somites. Dev. Dyn. 222: 506-521.

Seale, P., Sabourin, L.A., Girgis-Gabardo, A., Mansouri, A., Gruss, P., and Rudnicki, M.A. 2000. Pax7 is required for the specification of myogenic satellite cells. Cell 102: $777-$ 786.

Stockdale, F.E. 1992. Myogenic cell lineages. Dev. Biol. 154: 284-298.

Tajbakhsh, S. and Buckingham, M. 2000. The birth of muscle progenitor cells in the mouse: Spatiotemporal considerations. Curr. Top. Dev. Biol. 48: 225-268.

Tajbakhsh, S., Rocancourt, D., Cossu, G., and Buckingham, M. 1997. Redefining the genetic hierarchies controlling skeletal myogenesis: Pax3 and Myf-5 act upstream MyoD. Cell 89: 127-138. 


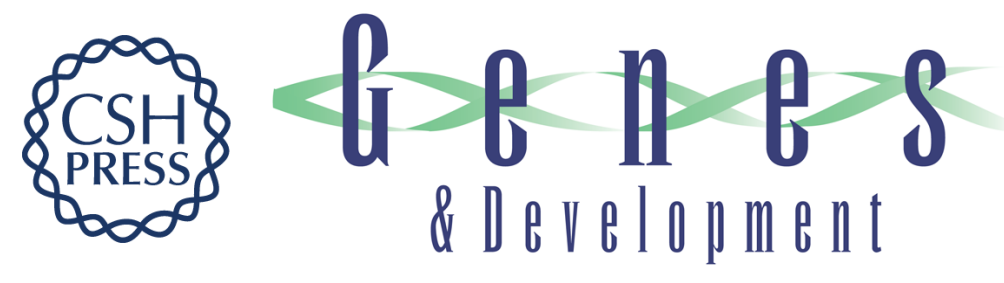

\section{The origin of embryonic and fetal myoblasts: a role of Pax3 and Pax7}

Graziella Messina and Giulio Cossu

Genes Dev. 2009, 23:

Access the most recent version at doi:10.1101/gad.1797009

References This article cites 34 articles, 13 of which can be accessed free at: http://genesdev.cshlp.org/content/23/8/902.full.html\#ref-list-1

License

Email Alerting Receive free email alerts when new articles cite this article - sign up in the box at the top Service right corner of the article or click here.

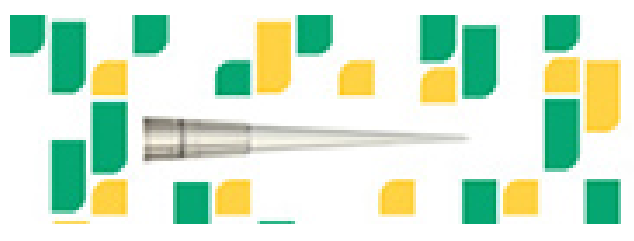

Focused on your science. 